\title{
NOTES ON NECROPHORIC BEHAVIOR IN THE ARCHAIC ANT MYRMECIA VINDEX (FORMICIDAE: MYRMECIINAE)*
}

\author{
By Caryl P. Haskins and Edna F. Haskins \\ 2100 M Street, N.W. \\ Washington, D.C.
}

\section{Introduction}

Ants of the Australian and New Caledonian genus Myrmecia apparently include the most archaic living Formicidae. Brown (1954) suggested that the genus may represent a relatively late evolutionary offshoot, specialized but fundamentally conservative, from a line of extremely generalized archaic forms represented as fossils by the genus Prionomyrmex of the Baltic amber and by the living Australian Nothomyrmecia macrops, of which only two workers have ever been found. Species of Myrmecia, therefore, may well illustrate the earliest patterns of Formicid social organization, and embody the most archaic patterns of Formicid social behavior, that we are likely to be able to study in detail in the laboratory or the field.

The bodily habitus of Prionomyrmex and Nothomyrmecia - not to mention of the far more archaic Mesozoic fossil genus Sphecomyrma first described by Wilson, Carpenter, and Brown (1967) which may well represent, as Wilson (I97I) suggests, an antecedent of the Myrmecioid complex of ants - all suggest active, epigeically foraging insects: a characteristic virtually universal in contemporary species of Myrmecia. This, combined with the fairly large size of the communities of many species of Myrmecia - specific counts of I 586 workers and over 2000 in total colony personnel have been made from larger colonies of $M$. gulosa (Haskins and Haskins, 1950) — raise the interesting question of how far these archaic forms may have evolved any pheromone-mediated patterns of communityintegrating behavior so conspicuous in many higher ants. This is an interesting and complex area of inquiry, the answers to which are far from obvious, as the recent investigations of Robertson suggest.

A prior question may be significant in this context. Do ants of the genus Myrmecia exhibit characteristic behavioral responses to particular chemical substances normally encountered in the external

*Manuscript received by the editor March 28, 1974. 
environment: substances which commonly evoke specific behavioral responses in higher ants? And if so are the responses elicited in Myrmecia essentially like those of higher ants?

We have recently described one such set of reactions: the stimulus to attack behavior in Myrmecia gulosa elicited by formic acid, a normal exocrine defense product of its common prey-genus Camponotus, but not, so far as can be determined, of $M$. gulosa itself (Haskins, Hewitt, and Haskins, 1973). The present investigation is concerned with the reactions of workers of a species of Myrmecia to substances which commonly stimulate necrophoric behavior in higher ants, such as oleic and related fatty acids.

Wilson (1958) and Wilson, Durlach, and Roth (1958) demonstrated that when groups of workers of the Myrmicine ant Pogonomyrmex badius come into contact with formic acid, ethylamine, triethanolamine, phenol, n-butyric acid, n-valeric acid, n-caproic acid, or n-caprylic acid, absorbed on centimeter-square patches of filter paper, they exhibit weak to moderate alarm behavior, sometimes passing into digging behavior, concentrated about the squares. In the case of oleic acid - and of that substance alone - the ants transported the paper squares away from the nest to the kitchen middens. A fatty acid component - quite probably oleic acidobtained from the decaying bodies of $P$. badius workers also elicited necrophoric behavior in Solenopsis saevissima.

Blum, Doolittle, and Beroza (cf. Blum, 1970) fractionated dead workers of Solenopsis saevissima and determined that the releasers of necrophoric behavior were restricted to the rich free fatty acid fractions. Myristoleic, palmitoleic, oleic, and linoleic acids were present in these fractions, and all these acids possessed necrophoric activity in this species.

Such a reaction to chemicals like oleic acid has obvious adaptive advantage for any ant, or indeed for any social insect inhabiting a closed nesting situation. Such chemicals can serve as sensitive "indicators" of objects in the nest - whether prey or remains of adult or immature members of the community - which are dangerously decomposed and should be removed. It seems plausible, therefore, that this behavior pattern may have been established very early in the social evolution of the Formicidae. Hence it seemed of particular interest to investigate it within the Myrmeciinae.

\section{Necrophoric Behavior in Myrmecia vindex}

The species Myrmecia vindex was chosen for several reasons. It is a common and wide-ranging form in western Australia, where 
it prefers open, partially xerophytic woodland habitats, but ranges much further, to South Australia and probably New South Wales and Victoria as well. It is an unusually hardy species and its colonies can be maintained in laboratory culture for many years. The primary reason for choosing it for this investigation, however, was that, in the populations from which nests were selected for both field and laboratory work, even mature colonies are typically quite small. ${ }^{1}$ This and other characteristics suggest that the species is one of the socially less-evolved members of the genus and thus lend particular interest both to the reactions of its workers to necrophoric substances and to pheromones of higher ants.

\section{Laboratory Tests}

Reactions of workers of Myrmecia vindex to Oleic Acid

A portion of a colony of $M$. vindex consisting of approximately 30 workers, 20 cocoons, and 25 larvae, collected at Kings Park, Perth, West Australia, on December 28, 1961, and long established in the laboratory in an earth-containing Lubbock type glass nest of dimensions $7^{\prime \prime} \times 12^{\prime \prime}$ and $3 / 4^{\prime \prime}$ in depth, was set up in a foraging arena consisting of a rectangular plastic box, $48^{\prime \prime} \times 24^{\prime \prime} \times 6.5^{\prime \prime}$ in inside dimensions, to which the ants had free access. The bottom of the arena was covered with clean brown paper.

After the colony had become thoroughly conditioned to the environment, piles of brood which had been impregnated with I to 2 drops of various substances were placed on cardboard sheets, $6 " \times$ 8 , at some distance from the nest entrance. There was early indi-

\footnotetext{
${ }^{1}$ Counts of four completely excavated apparently mature colonies from this population were made in January, 1964, with the following results:

Colony 111 typical brood female

21 callow subalates (apparent female-worker intermediates)

211 workers

Colony $4 \begin{array}{lll}1 & \text { typical brood female }\end{array}$

176 workers

Colony $6 \begin{array}{lll}6 & 1 & \text { typical brood female }\end{array}$

187 workers

Colony $7 \quad 1 \quad$ typical brood female

149 workers

This compares with a population count of a study nest of $M$. vindex reported by Douglas and McKenna (1970) as follows:

1 typical brood female

38 alate virgin females

38 dealate virgin females

210 workers

224 males
} 
cation that larvae were only marginally suitable for this work. Treated larvae were sometimes returned to the nest, as though larval odor, even when overlaid by that of oleic acid, still dominated behavior. With cocoons, however, worker reactions were more consistent.

At 5:30 p.m. two piles of Io larvae and Io cocoons each were placed on top of the Lubbock nest. The larvae were quickly restored to the nest. By 6:15 p.m., 5 cocoons of the untreated group had been transported to the nest, together with 3 from the fraction treated with oleic acid. By $6: 38$ p.m. all cocoons from the untreated pile had been transported to the nest, while no further oleic-acid-treated cocoons had been removed. By 8:55 the following morning, however, 4 of the oleic-acid-treated cocoons had been deposited in refuse middens in the arena, 2 being deposited $45^{\prime \prime}$ from the nest entrance and 2, $\mathrm{IO}^{\prime \prime}$ away. Three were still in original position on the cardboard, but had been well covered with earth. Earth grains obtained from inside the nest had also been deposited on spots of oleic acid which had drained from the cocoons to the cardboard.

The experiment was then repeated more precisely in the pattern of the work reported with $P$. badius. Ten squares of paper, $1 / 2 " \times$ $1 / 2^{\prime \prime}$, were soaked with ole:c acid and scattered at random over the surface of the nest, together with Io identical but untreated squares, appropriately identified. Two larvae, likewise treated with oleic acid, were included. The trial was begun at 9:10 a.m.

Workers coming into contact with the treated obiects immediately executed marked cleaning movements and a rubbing of the gular surface of the head against the substrate. At 9:20, I larva was picked up by a worker after much hesitation and held in the mandibles for 4 minutes, when it was grasped by a second. and then deposited by both at the nest entrance, but not taken inside. The impression of a conflict of drives was strong. One minute later this larva was again picked up, carried about $3^{\prime \prime}$ from the nest entrance, and dropped. By $9: 5.3$, it had been brought into the nest, while the second larva was held within $1 / 2$ ' later it also was brought into the nest.

At I0:00 a.m. a worker was beginning to deposit earth grains on the oleic-acid-treated papers, and by I0:5.2, 4. papers carried earth grains. By I :OO p.m., one of the treated larvae had again been brought out of the nest, and a worker was preparing to drop it on the midden located $45^{\prime \prime}$ from the entrance. By 5:00 p.m. both treated larvae were on this midden. Burying of the oleic acid squares continued but they were not moved toward the middens. 
At 5:Io p.m., 2 Tenebrionid larvae, I treated with oleic acid and the other untreated, were placed outside the nest entrance. At 5:13 p.m. the untreated larva was carried into the nest, and I minute later the treated larva also was seized and carried in. At 5:30 p.m., however, the treated larva was brought out, carried to a distance of $34^{\prime \prime}$, and discarded. The untreated larva was retained within the nest and shortly consumed.

These trials gave strong evidence that patterns both of burying and of rejection of objects impregnated with oleic acid are exhibited by $M$. vindex. It then seemed of interest to compare the reactions to oleic acid with those of other substances tested by Wilson et al. in their work with $P$. badius.

Reactions of workers of Myrmecia vindex to Methyl benzylamine; Caproic acid; Oleic acid; Formic acid

Using the same colony and with the same experimental arrangements as above, I4 cocoons, ranging from freshly spun to nearly ready to eclose, were impregnated as follows:

$\begin{array}{ll}\text { Methylbenzylamine (3 drops) } & 3 \text { cocoons } \\ \text { Caproic acid (3 drops) } & 3 \text { cocoons } \\ \text { Oleic acid (3 drops) } & 3 \text { cocoons } \\ \text { Formic acid } & 3 \text { cocoons }\end{array}$

2 cocoons were retained as controls.

All these cocoons were placed on cardboards, and mounted on top of the Lubbock nest as before, at 2:04 p.m.

At 2:19 p.m. the 2 controls and the 3 cocoons treated with formic acid had been permanently returned to the nest. At 5:40 p.m., I cocoon from the caproic acid group had been removed 40.5" from the nest and deposited on a refuse midden. All other cocoons remained untouched.

At 8:45 a.m. on March 3I, no further cocoons had been removed from the cardboards, but a few grains of earth had been deposited on the cardboards of the caproic- and oleic-acid treated objects. During the night the caproic-treated cocoon deposited on the refuse midden had been retrieved into the nest, but at $8: 55$ a.m. it was again brought out and carried to the midden, $44^{\prime \prime}$ from the nest entrance. Almost immediaeely it was again retrieved and returned to the nest. At 9:IO a.m., it was once more removed and dropped about $9^{\prime \prime}$ from the nest entrance. By $2: 03$ p.m. this cocoon had been carried to a midden $36^{\prime \prime}$ from the entrance, but I minute later 
it was returned to the nest once more, only to be finally removed by $2: 33$ p.m. and dropped about $32^{\prime \prime}$ from the nest entrance. At this time the 3 cocoons treated with oleic acid, the 3 treated with methylbenzylamine, and the remaining 2 treated with caproic acid were still in place on the cardboards, and a few grains of earth had been deposited about each. They were permanently ignored.

Reactions of workers of Myrmecia vindex to Triethanolamine: $\mathrm{n}-$ Valeric acid; Oleic acid

The same experimental arrangement was set up, using another colony of $M$. vindex, taken from the same population in Kings Park, Perth, West Australia, on January 10, 1965. Cocoons were treated as before:

$\begin{array}{ll}\text { Triethanolamine (3 drops) } & 3 \text { cocoons } \\ \text { n-Valeric acid (3 drops) } & 3 \text { cocoons } \\ \text { Oleic acid ( } 3 \text { drops) } & 3 \text { cocoons }\end{array}$

3 cocoons were retained as controls.

The 12 cocoons were arranged radially about the nest entrance, the control and the oleic acid groups furthest from it. Exposure was begun at 2:47 p.m.

Triethanolamine proved a powerful attractant, and the cocoons treated with it aroused immediate and intense attention. Within 3 minutes, I was dragged into the nest. At 2:5 I a second triethanolamine-treated cocoon was dragged to the nest enerance and dropped. At 2:52 the third was carried to the oleic-acid-treated group outside the nest and dropped there. Two control cocoons were carried into the nest at the same time. A spot of triethanolamine stain on the containing card was repeatedly examined by workers.

The second triethanolamine-treated cocoon, which was deposited initially near the nest entrance, at 2:56 p.m. was carried to a midden 45.5" away; it was then picked up almost immediately and redeposited at a distance of 40" . At 3:02 the triethanolamine-treated cocoon which had first been brought into the nest was taken out, carried to a point about 9" away, and dropped. Earth grains had been deposited about the n-valeric acid group. The 3 oleic-acidtreated cocoons had not been moved nor buried. By $4: 00$ p.m. all three triethanolamine-treated cocoons had been discarded in a group $39^{\prime \prime}$ from the nest entrance; I control cocoon was still in place; and all 6 cocoons treated with n-valeric and oleic acid remained in their initial position. At 4:50 p.m. there had been no further change and the run was terminated. 
On April 2, 1965, the same experiment was repeated, substituting n-butyric for n-valeric acid. Results were essentially the same. Fiftyfive minutes after the start, 3 of the 4 triethanolamine-treated cocoons had been transported for distances of $4 \mathrm{O}^{\prime \prime}, 2 \mathrm{I}^{\prime \prime}$, and $25.5^{\prime \prime}$ from the nest entrance and dropped; although none of the n-butyric or oleic acid cocoons had been moved, there was a considerable deposit of earth particles about them. One control cocoon had been moved about 2", but none had been carried into the nest. Twenty minutes later, the triethanolamine group was still being moved at frequent intervals, and the oleic acid group was being heavily banked with earth grains. No attention was paid to the n-butyric acid groups.

The strong impression left by these trials, and others like them, was that oleic acid, and to a lesser degree caproic acid stimulate in Myrmecia vindex both a burying reaction and sometimes the transport of objects so contaminated to refuse middens. No evidence of overt digging was seen. Formic acid seemed without effect. Triethanolamine, however, functioned as an efficient excitant and attractant in higher concentrations. In lower concentrations it stimulated necrophoric behavior. The "conflict" behavior exhibited in the handling of some larvae and cocoons treated with several of these substances, when immatures were repeatedly taken into the nest, brought out again and discarded on a midden, then returned to the nest, sometimes through three or four cycles, was in several cases striking.

\section{Field Tests}

Reactions of workers of Myrmecia vindex to Oleic acid;

Caproic acid; Formic tcid; Methylbenzylamine

It was of interest to conduct essentially similar tests with wild colonies in the field. A large and active colony of $M$. vindex in Kings Park, Perth, West Australia (a part of the same population from which the colonies had been taken for laboratory tests), was selected. It included approximately 200 workers, had a single large entrance-hole, and a well-defined crater. Since workers of this population show a predominantly crepuscular and nocturnal foraging pattern in warm weather, tests were begun in the evening.

At $7: 25$ p.m., as dusk was gathering, 5 white cards, of dimensions $3^{\prime \prime} \times 5^{\prime \prime}$, were mounted on the nest crater, approximately equidistant from the entrance. Twenty-five cocoons, obtained from a neighboring colony, were impregnated with 3 drops of test substance, with 7 retained as untreated controls. The arrangement and treatments were as shown below: 


$\begin{array}{ccl}\text { Card Marking } & \text { No. of Cocoons } & \text { Substances Impregnated } \\ \text { C } & 7 & \text { Caproic acid } \\ \text { F } & 6 & \text { Formic acid } \\ \text { M } & 7 & \text { Methyl benzylamine } \\ \text { O } & 5 & \text { Oleic acid } \\ \text { L } & 7 & \text { Control }\end{array}$

Immediately on exposure a worker on the crater seized one control and dragged it inside the nest. A second worker, encountering an oleic-acid-treated cocoon, started away. At 7:32, I caproic-acidtreated cocoon was dragged into the nest, followed at $7: 35$ by a second control cocoon. At 7:37 a cocoon from the formic acid group was taken to the nest. Between $7: 37$ and $7: 40,3$ additional formicacid-treated cocoons were taken into the nest, and one-half minute later the last control cocoon was taken in. One of the remaining two formic acid cocoons was inadvertently toppled into the nest by another worker, leaving I on the card. The other groups were untouched. At 8:02 p.m., when darkness forced cessation of observation, all cocoons treated with oleic acid, methylbenzylamine, and five of those with caproic acid remained in place on the cards. One cocoon treated with caproic acid had been deposited with the oleicacid-treated group.

At 6:00 a.m. the following day, 3 of the caproic-acid-treated cocoons had been removed, but it was not possible to determine whether they had been taken into the nest or discarded. Some grains of earth had been scattered on the caproic-acid-treated card.

Observations were continued throughout the day, but no further attention was paid to the remaining cocoons. However, when the cards were removed from the crater at 7:00 a.m. on the third day, it was found that a new entrance-hole had been excavated under the card carrying the oleic-acid-treated cocoons.

It was clear that oleic acid, caproic acid, and methylbenzylamine effectively inhibited return of the cocoons to the nest by the workers, in marked contrast to those treated with formic acid and the controls, which were brought in promptly. Digging behavior was observed in the vicinity of oleic acid. In these experiments, however, the oleic acid objects were not buried nor transported to kitchen middens perhaps because such middens of $M$. vindex are often located near the nest entrance. Indeed. it is an interesting behavioral characteristic of $M$. vindex, at least in this population that, at the seasons of maximum brood production, empty cocoons and pupal exuviae are frequently piled near the nest entrance. That this disposition may be more than accidental is suggested by the behavior of some colonies 
in the laboratory (not those with which the above-mentioned tests were conducted), where such exuviae, originally scattered about a foraging arena, may be gathered into dense craters about the entrances to Lubbock nests.

\section{Summary and Conclusions}

In a parallel series of experiments to those reported by Wilson (1958) and Wilson, Durlach, and Roth (1958) with Pogonomyrmex badius, the effects of oleic acid, caproic acid, methylbenzylamine, n-butyric acid, n-valeric acid, formic acid, and triethanolamine as behavioral releasers in the ant Myrmecia vindex were investigated both in the laboratory and the field. The comparison was deemed particularly interesting because of the archaic character of the Myrmeciinae and their societies.

As with Pogonomyrmex and other higher Formicid genera, oleic acid was found to act as a releaser of both necrophoric and digging behavior, suggesting the early establishment of this set of reaction patterns in Formicid social evolution - a not unexpected situation in view of the highly adaptive character of this pattern in ridding the nests of dangerous animal decomposition products, perhaps in response to the bacterial production of oleic and related fatty acids. In Pogonomyrmex, n-butyric acid, n-valeric acid, and n-caproic acid stimulated weak to moderate alarm behavior, passing over into digging behavior. In Myrmecia, caproic acid stimulated mildly necrophoric behavior, associated with some digging and burying behavior. Exposure to filter papers of cocoons impregnated with n-butyric acid resulted in deposition of earth grains on the treated object. No reaction was observed to n-valeric acid.

Thus responses to these substances were of the same general quality as those reported for $P$. badius. There were, however, very marked differences in the responses of $M$. vindex to two presumed releasing substances: formic acid and triethanolamine. Formic acid neither stimulated necrophoric nor digging behavior nor prevented immediate transport into the nest of formic-acid-treated cocoons. This result was somewhat surprising to the authors in view of the highly positive and specific attack reactions stimulated by formic acid in Myrmecia gulosa mentioned earlier, which have been reported elsewhere (Haskins, Hewitt, and Haskins, 1973). The most marked contrast between behavior patterns of $P$. badius and $M$. vindex, however, occurred with those released by triethanolamine. With $M$. vindex, vapors of this compound consistently stimuated the most conspicuous necrophoric behavior of any substance tested, while also acting as a 
decided attractant. In P. badius on the contrary, the reaction to triethanolamine was reported to be virtually neutral.

In this connection it is interesting to note that, in the populations studied, $M$. vindex commonly piles discarded cocoons and pupal exuviae on the crater of the nest, near the entrance, where they characteristically accumulate in some numbers, rather than transporting them far afield. Similar behavior has been described for $P$. badius (Wilson, Furlach, and Roth, I958), though in the latter case, removal of the discards is quickly accomplished by other foraging ants. The situation with $M$. vindex, however, appears more specific. Indeed established colonies in the artificial nest may collect discarded cocoons and pupal exuviae scattered about the foraging area to form a crater about the entrance. It may be that subtle behavioral balances are involved, depending on the nature and "mix" of the included decomposition products, as suggested by the reversal of behavior, apparently in response to vapor concentration, released by triethanolamine.

\section{REFERENCES}

Blum, Murray S. The chemical basis of insect sociality. From Chemicals Controlling In sect Behavior. Academic Press, New York, 1970, pp 61-94.

Brown, William L., JR. Remarks on the internal phylogeny and subfamily classification of the family Formicidae. Insectes Sociaux. 1, 1, 1954, pp 21-31.

Douglas, Athol M. and L. M. McKenna. Observations on the bull-dog ant, Myrmecia vindex. The Western Australian Naturalist, 11, no. 6, pp 125-129, 1970.

Haskins, Caryl P., Richard E. Hewitt, and Edna F. Haskins. Release of aggressive and capture behavior in the ant Myrmecia gulosa by exocrine products of the ant Camponotus. Jour. Ent. (Royal Ent. Soc., Great Britain) (A), 47 (2), pp 125-139, 1973.

Haskins, Caryl P. and Edna F. Haskins. Notes on the biology and social behavior of the archaic Ponerine ants of the genera Myrmecia and Promyrmecia. Ann. Ent. Soc. of Am. 43, 4, December, 1950, pp 461-491.

Robertson, Phyllis L. Pheromones involved in aggressive behavior in the ant Myrmecia gulosa. Jour. Insect Physiol. 17, 1971, pp 691-715.

Wilson, EdWARD O. A chemical releaser of alarm and digging behavior in the ant Pogonomyrmex badius (Latreille). Psyche 65, 2-3, JuneSeptember, 1959, pp 41-51.

WILson, EDWARD O. The Insect Societies. Harvard University Press, Cambridge, Mass. 1971, pp 31-32. (Origin of Ants, Sphecomyrma and Myrmecioid complex).

Wilson, Edward O., Frank M. Carpenter, and William L. Brown, Jr. The first Mesozoic ants. Science, 157, September, 1967, pp 1038-1039.

Wilson, Edward O., N. I. Durlach, and L. M. Roth. Chemical releasers of necrophoric behavior in ants. Psyche, 65, 4, December, $1958 \mathrm{pp}$ 108-114. 

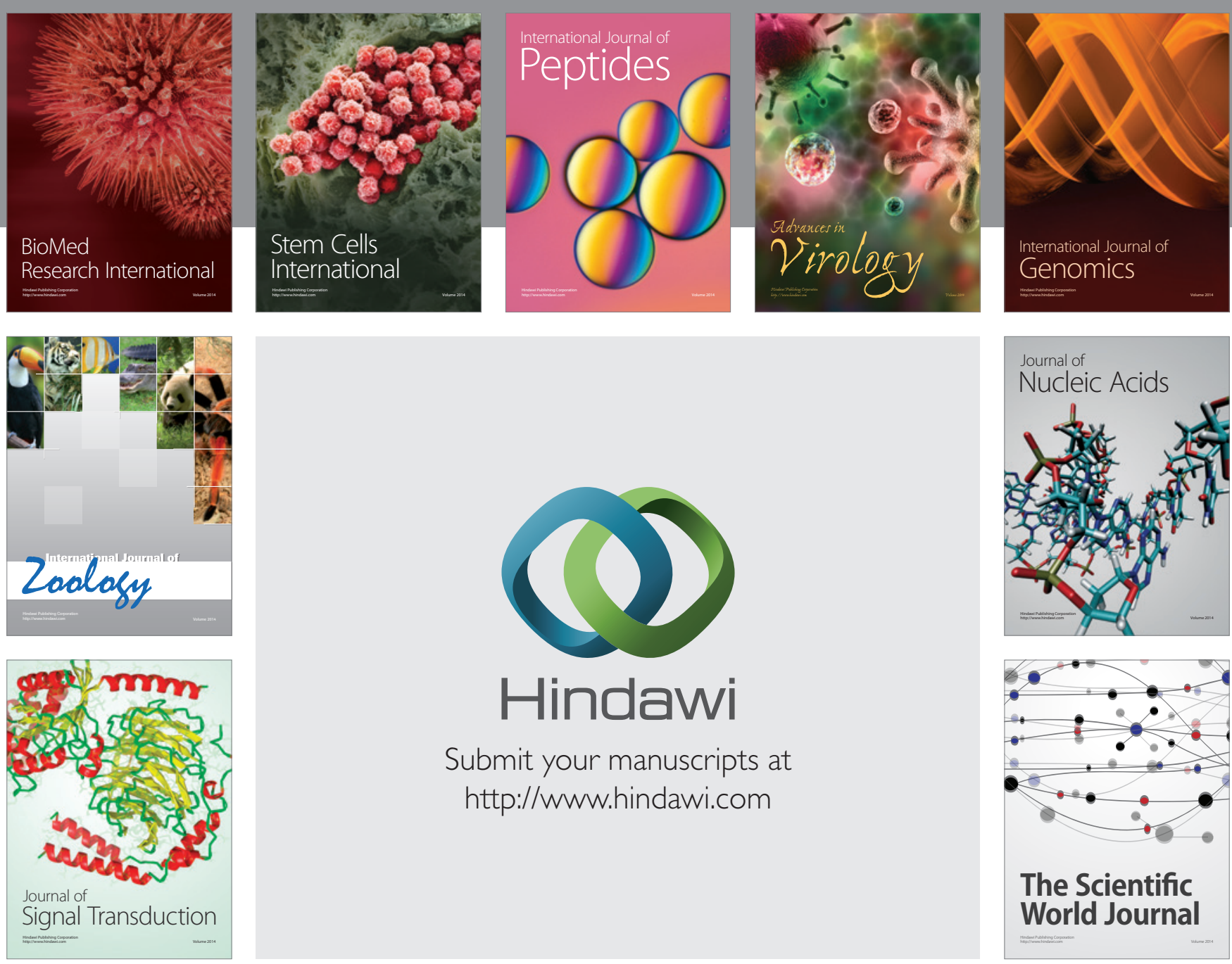

Submit your manuscripts at

http://www.hindawi.com
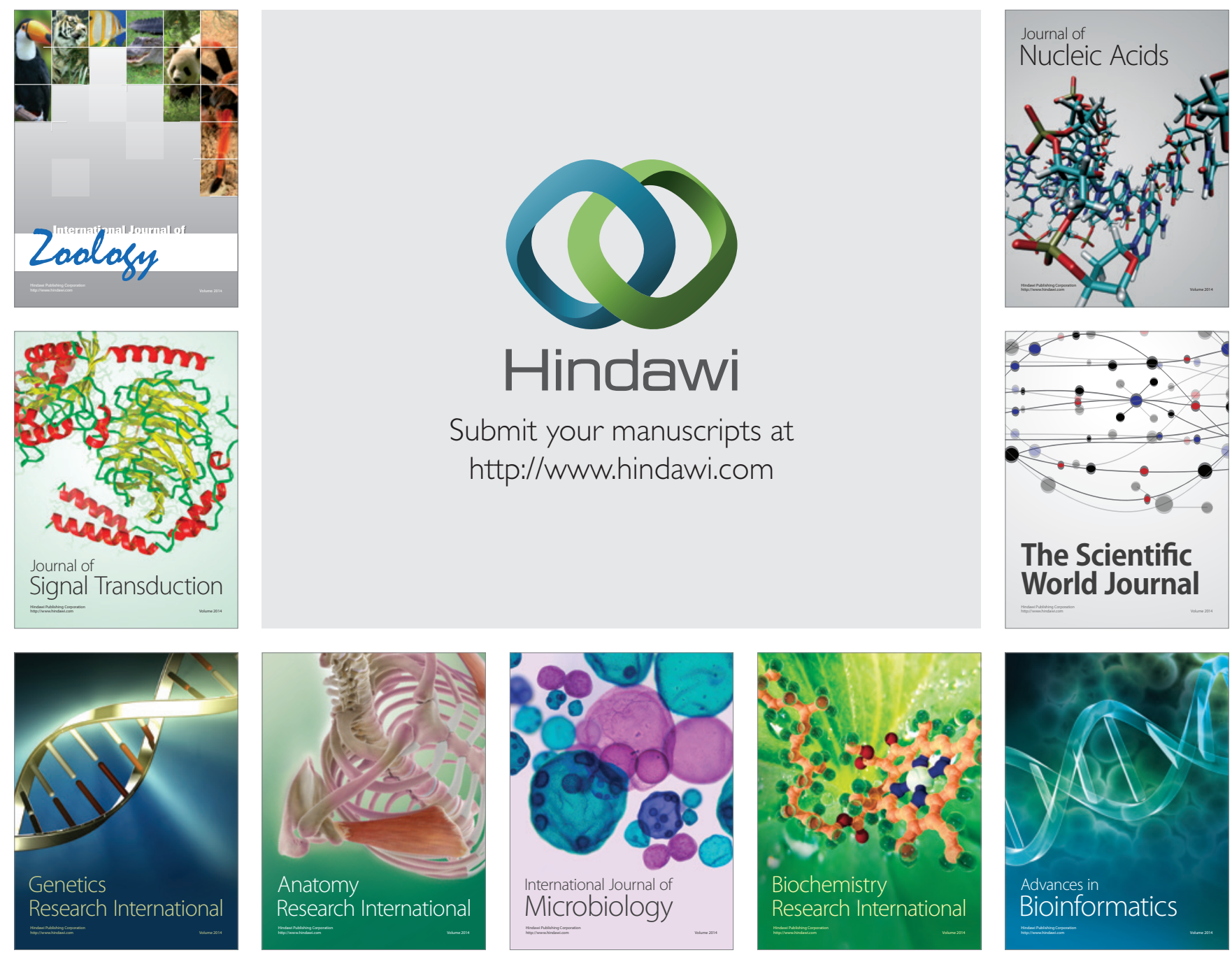

The Scientific World Journal
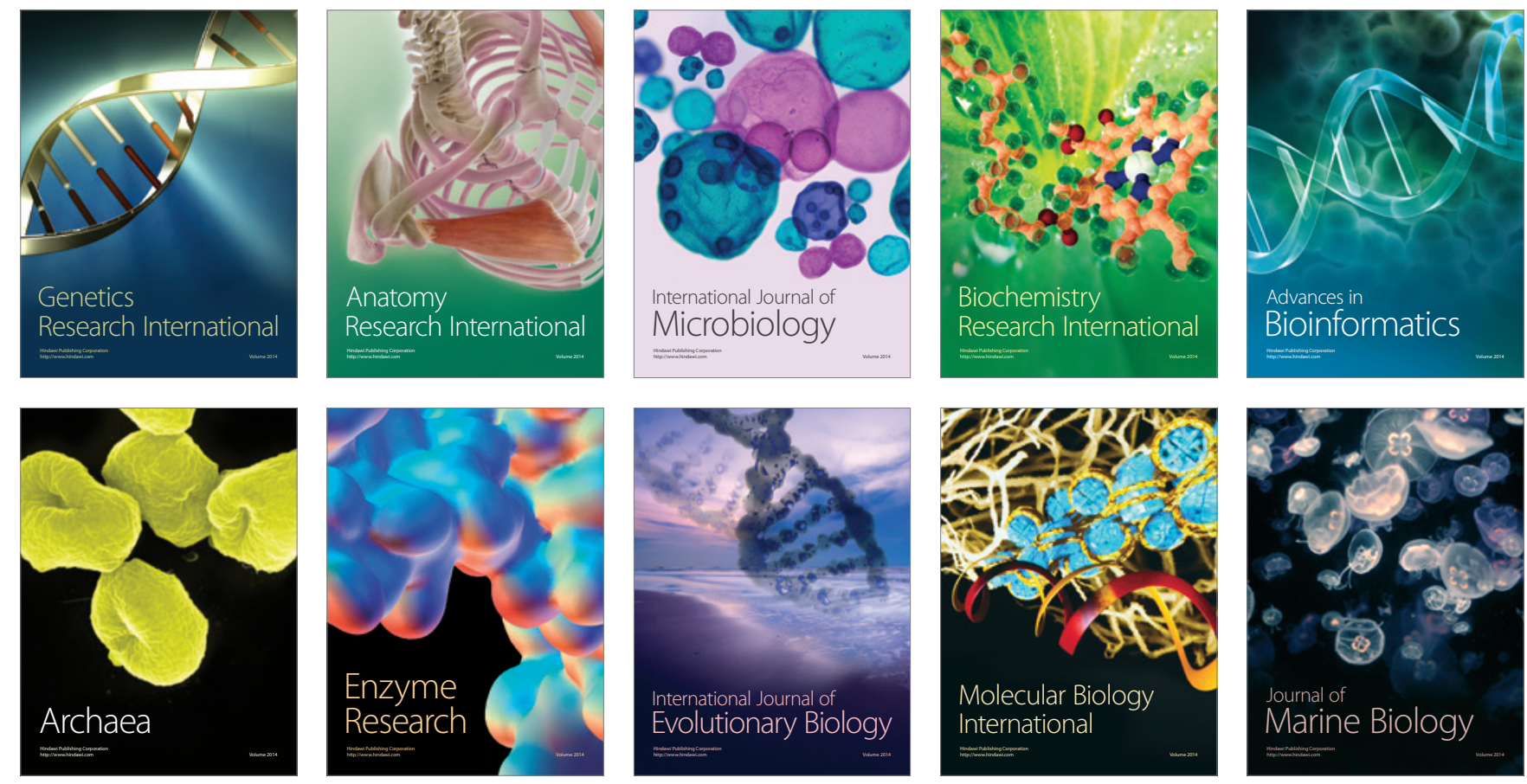